\title{
How to favour know-how transfer from experienced teachers to novices?
}

\author{
Thierry Condamines \\ Knowledge Team of the Modelling, Information and Systems (MIS) \\ laboratory, Université of Picardie Jules Verne, 33 rue Saint Leu, 80039 \\ Amiens Cedex 1, France. \\ thierry.condamines@amiens.iufm.fr
}

\begin{abstract}
The first years in a teacher's career are known to be very hard. In fact, know-how, resulting from experience, is rather poor. And at the same time, there are seeds of know-how distributed in each experienced teacher and constituting a real gold mine. Finding the means of transferring this know-how constitutes a challenge for the knowledge society. We propose here a solution based on a know-how capitalization using both a knowledge base and a case base. Know-how is collected from a large number of experts, using collection scenarii. In addition, as it's impossible to collect all know-how, problems encountered by novices are discussed with selected experts and, when solutions are found, the cases are stored in a case base.
\end{abstract}

\section{Introduction}

In many countries, young teachers' professional identity construction is an increasingly important concern. The control of all knowledge necessary for this work is difficult bringing teachers, during the first years of their career, to balance between pleasure and suffering, and sometimes to resign. According to Saujat [1], young teachers must face a double training: that of their pupils and theirs.

While it's easy enough for a teacher to increase his knowledge on subjects like mathematics, history or physics, it's more difficult to learn class management for example. It's a field where young teachers have the poorest knowledge or, when knowledge exists, it often rests on false representations coming from their own experience as pupils. Unfortunately it's difficult to teach this kind of knowledge at university because it comes primarily from experience which, by definition, is absent at the beginning. And beside that, there is a gold mine of know-how distributed in each experienced teacher. Thus how can we effectively prepare young teachers with class reality, making them able to face every day difficulties and unforeseen situations? 


\section{Knowledge transfer from experienced teachers}

According to Nonaka [2], teachers' know-how belongs to tacit knowledge and is difficult to formalize and communicate. It can be shared by oral communication or observation of experienced teachers in action: how to control noisy children, conflicts. According to Tardif [3], a teacher employs routines built by a trial and error approach to react to new situations, which enable him to pay more attention to children learning.

The first idea is to say that if know-how is difficult to formalize, it can be learned by observation. But a teacher has to manage his own class and has no time for observation. Another way is to discuss with experienced colleagues in the same school. But this implies to show its weaknesses and, in fact, when we question young teachers on this subject, we note that discussions are very limited because of a fear to be perceived like an inefficient teacher by colleagues. A third way is tested in Canada. It's a "mentor" program where an experienced teacher follows a novice over a long period. Studies enumerated in [4] show the interest of such a program. But a problem is that it's difficult and complex to find a mentor adapted to a particular beginner. Moreover, the beginner can copy the mentor, without a sufficient reflexive analysis. Another approach is based on electronic forums. It can be forums between only beginners or with participation of some experts. The main problem of this process, quoted by Depover [5], is that the artefact gives a very poor structure to discussions. Thus knowledge is drowned in the flood of messages.

\section{A know-how capitalization approach}

To try to find a solution, we turned to the industry world where techniques of knowledge management were developed to identify and store crucial knowledge of experts and make it available for new workers, new projects. But can we compare knowledge necessary to manufacture an object with knowledge for class management? In our case we are confronted with knowledge very difficult to model because we are not in a technical field but in human sciences. This difficulty is proven by the little of work on this subject. These works are generally based on capitalization of explicit knowledge by indexing [6] or annotation [7] of texts. Others as [8] are based on a computer supported collaborative work to exchange knowledge. About tacit knowledge for teachers we can quote the IPAS project [9], where knowledge is exchanged in the field of pedagogical scenarii construction, and the TeCap project [10], based on a community of practice for online tutors in a distance learning system.

\subsection{Expertise seeds}

Each teacher, thanks to a pedagogical freedom, has built a very effective individual know-how. Thus our postulate is that there is not a small list of wellknown experts (which is often the case in an industrial field) but on the contrary, "expertise seeds" disseminated in the population of experienced teachers. If we 
consider only a "representative" list of experts we will have to face an important loss of knowledge.

This scattering of expertise seeds makes them difficult to identify and collect. The first stage of our work is then to find a process to collect them at a large scale. Traditional methods based on discussions with some experts cannot be employed here. Our approach is based on three stages:

- to identify crucial know-how by discussions with young teachers, experienced teachers and the observation of discussion forums. For example: how to manage workshops in a nursery school?

- to characterize each know-how. For example for a workshop: composition of groups, duration, subjects, place of the teacher, instructions, evaluation

- to build a collection scenario for each know-how. From the characteristics of a know-how, we build a tree structure questionnaire.

The collection at a large scale brings a certain richness but raises the question of the value of these know-how seeds. If it's quite easy to evaluate knowledge implied in the manufacture of objects, it's more difficult in human sciences. An a priori evaluation is impossible. We thus chose an evaluation of this knowledge on the level of its use by the beginner. For example, when a beginner wonders how to manage workshops, the system returns several ways of doing it (coming from several experts). He chooses the most appropriate one (with his situation, his character). Then, following its implementation in his class, he will be able to give an evaluation.

\subsection{Case base reasoning}

Know-how, in particular in class management, is often related to a quite precise situation and often corresponds to the solution of an encountered problem. We cannot a priori capitalize all know-how allowing to solve all the problems. To help a beginner, an expert must know the context with precision to give a possible answer to the problem. This is why we use a case base to enrich our base.

The beginner describes his problem with precision. If elements appear in the knowledge base or similar cases in the case base, they are returned. If he is not satisfied, the case is put on standby and sent towards several adapted experts. The beginner exchanges then with the experts until a solution which is appropriate to him is found. The solved problem is then put in the case base.

\subsection{Importance of a teacher profile}

It's crucial to define a teacher profile to allow to measure the degree of expertise of a teacher (general experience, experience in the current class, domain of expertise, utilization ratio and evaluation of his know-how,...), to connect an expert adapted to a beginner (type of school, type of class,...), to return a knowledge adapted to a request. It's a dynamic profile which is constantly updated. For example, a teacher works in a urban nursery school (in a difficult social area, with 5 classes) for 10 years, has 4 years old pupils for 5 years with sometimes a handicapped one, 28 children in the class. He prefers teaching mathematics and science. His know-how evaluations are: discipline (30\%), workshop management $(80 \%)$. 


\section{Conclusion}

Know-how transfer from experienced teachers to novices is an important challenge for the knowledge society. A huge progress has been made in industrial applications of Knowledge Management but a lot of work has to be made in Education. A system based on knowledge capitalization and case base reasoning seems to be interesting for several reasons:

- to preserve know-how of experienced teachers even if they stop working (retirement,...);

- to tutor young teachers ;

- to allow pedagogical innovation starting from existing know-how;

- to allow education managers to better know what problems are really encountered by teachers and to optimize their decisions (lifelong training programs,...);

- to identify good practices.

Our experiments are at their beginning and the results, although encouraging, require being refined. We also work on a domain ontology allowing a better knowledge management (indexing, research) and the use of inferences.

\section{References}

1. F. Saujat, Spécificité de l'activité d'enseignants débutants et genre de l'activité professorale, Polifonia, $\mathrm{N}^{\circ}$ 8, pp. 67-93 (2004).

2. I. Nonaka, and H. Takeuchi, The knowledge-creating company : How Japanese Companies Create the Dynamics of Innovation (Oxford University Press, 1995).

3. M. Tardif, and C. Lessard, Le travail enseignant au quotidien. Expérience, interactions humaines et dilemmes professionnels (De Boeck, 1999).

4. C. Bergevin, and S. Martineau, Le mentorat (2007); http://www.insertion.qc.ca/ article.php3?id_article $=126$

5. Ch. Depover, B. De Lievre, and G. Temperman, Points de vue sur les échanges électroniques et leurs usages en formation à distance, Sciences et Technologies de l'Information et de la Communication pour l'Education et la Formation (STICEF), Vol. 13 (2006).

6. M.H. Abel, A. Benayache, D. Lenne, and C. Moulin, E-MEMORAe : A content-oriented environment for e-earning, E-Learning Networked Environments and Architectures : A Knowledge Processing Perspective (Springer, 2005).

7. F. Azouazou, and C. Desmoulins, Teachers Document Annotating : Models for a Digital Memory Tool , Int. J. Cont. Engineering Education and Lifelong Learning (IJCEELL), 16 (1/2), pp. 18-34 (2006).

8. J. Carroll, et al., Knowledge Management Support for Teachers, Educational Technology Research and Development, 51 (4), pp. $42-64$ (2003).

9. Tzu-Chien Liu, and Yih-Ruey Juang, IPAS - Teacher's knowledge management platform for teachers professional development, the International Onference on Engineering Education, Manchester, England, August 18-22 (2002)

10.E. Garrot, S. George, and P. Prevot, "The development of TE-Cap: an Assistance Environment for Online Tutors", $2^{\text {nd }}$ European Conference on Technology Enhanced Learning (EC-TEL 2007), Crete, Greece, Sept. 17-20 (2007). 